\title{
LA TIERRA ANDALUZA: ETHOS Y RELACIÓN CON EL CONCEPTO DE PODER
}

\author{
Rosalia MARTÍNEZ *
}

\section{INTRODUCCIÓN: PODER Y GRUPOS SOCIALES}

La riqueza agraria de Andalucía contrasta desde el Antiguo Régimen con la pobreza, y en muchas ocasiones situción de subsistencia, del pueblo, que continuamente se revela contra las estructuras agrarias béticas desde el siglo XVII hasta las agitaciones campesinas de finales del XIX y principios del XX, pasando por las quejas de Olavide en el XVIII, hasta los agraristas de preguerra ocupados en el problema del latifundismo y a la actualidad con los tres problemas andaluces del momento, que serían la debilidad relativa de la renta per capita, el paro y la emigración.

La oligarquía agraria se compone de un conjunto de escasos individuos- no de instituciones- que proceden de la nobleza o de la gran burguesía terrateniente y compradora de tierras bajo la desamortización. La mayor parte de las tierras de esta burguesia procedia de compras más que de herencia, aunque un tercio de ellas sí se puede considerar de esta procedencia por el carácter endogámico de los terratenientes y su afán de entroncar con la nobleza.

Respecto a la situación de las clases humildes nos comenta Malefakis lo siguiente acerca de los abusos de los propietarios, que eran probablemente los causantes de la propensión a la rebeldia de los pequeños arrendatarios del Sur: "Los elevados alquileres, la brevedad de los contratos de arriendo, los frecuentes subarriendos... La principal tragedia del Sur consistía en que debido a la herecia latifundista, que impedia el desarrollo de las pequeñas explotaciones familiares, el estrato social predominante no estaba formado por pequeños propietarios, sino por jornaleros sin tierra (...). La miseria y la inseguridad de la mayoría de los jornaleros eran suficientemete grandes como para convertirles en el único grupo implicitamente revolucionario de la sociedad rural española (...) constituyendo la fuente de la que manaban las convulsiones sociales que barrían el Sur"l.

* Doctora en Geografía e Historia. Sección Antropología Social.

1. MALEFAKIS, E. Reforma agraria y revolución campesina en la España del siglo XX, Ed. Ariel, Barcelona, 1976, pp. 86 y ss. 
Esta tedencia a concentrar y monopolizar tierras acentuó y multiplicó los conflictos sociales en el mundo rural, especialmente en las zonas latifundistas, haciendo asimismo mas evidente la situación de dicotomía social que había caracterizado a la región, y que a partir de ahora iba a provocar una mayor concienciación y una toma de postura más claramente comprometida y radical entre individuos de otras clases sociales andaluzas que no eran las directamente afectadas por el problema.

El problema de la tierra, es decir, la lucha entre los que la poseen y los que la desean, pasa a formar parte de las formas de vida de los andaluces y por consiguiente a influir en su forma de ver el mundo y de sentirlo.

En la época que estudiamos, primer tercio del siglo $\mathrm{XX}$ con las nuevas ideologías sobre igualdad de la propiedad y la fuerza de las capas populares, cada vez más organizadas, la idea del reparto va tomando fuerza y forma.

Se agudiza el enfrentamiento entre poseedores y desposeidos.

Creemos que, en la relación andaluces-tierra-poder, se crea un circulo vicioso, o un proceso de feed-back, pues cuanto más poder adquiere la oligarquía terrateniente a través de la posesión de las tierras, más ansia de posesión de estas hace surgir entre los que no la tienen, que ya se ven con los mismos derechos a detentar ese poder político que hasta entonces les había parecido inalcanzable, inmersos como estaban en un universo de determinadas ideas impuestas en el cual todo se percibía como inconmovible y mandado por Dios.

Respecto a esto y a la percepción que el poder va tomando sobre ello, puede leerse un texto, escrito como prólogo a la novela de J. Andrés Vazquez - Ese sol, padre y tirano - (1908), en el que Joaquín Agudelo Herrero escribe:

"En los inicios del siglo XX, pese al fracaso de las huelgas generales, las masas obreras estuvieron fuertemete unidas, La agitación obrera en aquel momento adquiere un relieve considerable. El gobierno contempló con serenidad los sucesos, en vez de utilizar las represiones anteriores, y los dirigentes del país intentaron investigar los problemas económicos y jurídicos de aquella triste situación del jornalero. En 1903 fué creado el Instituto de Reformas Sociales para estudiar Ia cuestión agraria. La prensa, el Ateneo de Madrid y las Cortes hablaban constantemente del tema en aquellos años"2.

Mucho se sabe de los propietarios y de sus tierras en cuanto a datos, pero no podemos dejar atras el intentar aportar algunos sobre los menos favorecidos de esta sociedad. Vuelve a ser Pascual Carrión, tan preocupado por el problema social que conlleva la estructura agraria andaluza el que nos acerca a la realidad de esta otra parte de la sociedad:

"La región Bética o valle del Guadalquivir, tiene 155.600 familias sin tierra, 164.342 que no reunen más de 5 hectáreas, y 187.542 que no pasan de 10 has; así

2. VAZQUEZ, J.A. Ese sol padre y tirano... Novela de la sequía de 1905, Editoriales Andaluzas Unidas, S.A., 1984. 
es que presenta e total 343.000 familias de agricultores necesitados de tierra, según estos cálculos"3.

Si en la estructura económica se producen cambios en este paso de un siglo a otro, no se puede decir lo mismo en lo referente a la evolución social. La situación de este campesinado será el germen más importante de desestabilización y conflicto social en el primer cuarto del siglo $\mathrm{XX}$, sin que haya intención alguna por parte del poder de poner en cuestión las estructuras agrarias, que solo serán atacadas desde el campesinado mediante impulsos de movimientos huelguísticos e insurrecciones de distinta intensidad y escasa duración.

Estos movimientos, si por un lado no logran el objetivo propuesto, es decir la reforma agraria, si tuvieron importancia en la progresiva toma de conciencia de clase y de los problemas regionales y del país por parte de la clase obrera, que ya es capaz de enfrentarse con las estructuras oligárquicas dominantes desde posturas ideológicas más contundentes, originadas por la difusión de las nuevas ideas de izquierda y el auge del sindicalismo y asociacionismo obrero.

La división entre propietarios y no propietarios sirve para deslindar grupos sociales y definir su participación en el poder. El propietario es, según las leyes fiscales y contriburivas del Estado, el protagonista de la vida económica. También lo es de la vida política pues como ciudadano-contribuyente estuvo acostumbrado a mandar mediante su influencia en el sufragio censitario hasta 1890 y despues mediante compras de cargos para sus fieles. En definitiva los mayores contribuyentes por rentas de la tierra constituyen el eje divisorio de la más importante discriminación social ${ }^{4}$.

Cuando se habla de división entre propietarios y no propietarios estamos hablando de la estructura social de la región. Cuando se habla del ciudadano-contribuyente, estamos entrando en el tema del poder, un poder basado en la propiedad de la tierra, base de la citada discriminación social.

En Andalucía el sistema de propiedad ha estado anquilosado desde los cambios que se produjeron mediante las sucesivas desamortizaciones, y el poder jurídico, que continuamente está en movimiento, no ha querido, en cambio, mover nada sobre este tema. Ello se ha debido fundamentalmente a dos razones: a defender los intereses individuales de los propietarios establecidos, que normalmente tienen relaciones estrechas con este poder, mientras al mismo tiempo se pretende no remover otros intereses heridos. Por otra parte, se teme caer en un caos en cuanto se refiere a la producción, de por sí bastante precaria en la España de la época. Se teme que al tocar las bases de la propiedad, se derrumbe la economía agraria.

3. CARRION, P. Los latigundios en España. Su importancia, origen, consecuencias y solución, Prólogo de Fernando de los Rios, Madrid, 1932, pp. 389-391.

4. MARTINEZ CUADRADO, M. La burguesia conservadora 1874-1931, Ed. Alianza Universidad, Madrid, 1979, pp. 278. 
"Obvio es decir que los grandes propietarios del campo, la alta burguesía agraria formada a través de los procesos desvinculatorios del siglo XIX (parte de la cual era noble, los antiguos señores; otra, burguesía de extracción posterior) era el sector dominante"s.

Todas estas "familias", intimamente relacionadas (por enlaces matrimoniales) y estrechamente imbricadas en sus negocios e intereses, manejaban a un tiempo los resortes de la gran propiedad agraria, de las finanzas y de los negocios. Constituian el máximo status de la vida social española, y consecuentemente su influencia en el poder político era grande.

Los intelectuales, muchas veces desclasados, o al menos en una posición ideológica y vital que no encuentra sitio definido entre los grupos sociales reconocidos en la época, se constituyen en grupúsculo social con pretensiones de influencia ideológica sobre las clases altas y sobre las bajas.

En base a nuestro estudio, podemos decir respecto a Andalucía, que dentro de este grupúsculo social, algunos intelectuales empezarían a tener una actuación de crítica a esa oligarquía, cuyo papel no habían puesto en tela de juicio anteriormente, y se convierten, no todos por supuesto, en denunciantes de una realidad social y económica, que no aceptan, a través de artículos, ensayos, novelas, poemas, cartas, posiciones ideológicas y políticas concretas, y modos de vida y relaciones que a alguno llegó a costarle la pérdida de su carrera, su posición social e, incluso, su vida.

La oligarquía detentaba el poder en todas sus formas y campos, pero hay que destacar que era apoyada por otro poder de gran alcance en distintas realidades históricas debido a la importancia en fuerza y difusión de su aparato ideològico: la Iglesia.

En efecto, independientemente de su esencialidad religiosa, la Iglesia detentaba su hegemonía sutilmente, con un trabajo de mentalización desde el púlpito, a través de los sermones (podemos ver un ejemplo de ello en la novela Juanita la Lar$\mathrm{ga}^{6}$, en que el párroco, desde el púlpito, recrimina a la protagonista, de clase humilde, por atreverse a vestir como una dama de alcurnia),. Y más directamente, una vez que la situación se puso "peor" con el advenimiento de las masas populares al protagonismo histórico, lo intentaría a través de los Sindicatos Católicos, cuyo fin era frenar el avance de las ideas y acciones socialistas.

Por tradición y por intereses propios, la Iglesia siempre había sido la más ferviente defensora del orden establecido, que explicaba como de origen divino, y durante siglos había sido el órgano legitimador del poder y encargada de la reproducción y fijación de valores e ideas.

5. TUÑON DE LARA, M. "De la Restauración al desastre colonial", en Historia 16, Extra XXII, pp. 62.

6. VALERA, J. Juanita la Larga, Ed. Castalia, Madric, 1986. 
A principios de siglo la enseñanza primaria, la socialización, estaba totalmente en manos de la Iglesia, ya que era totalmente desatendida por los poderes públicos; e igualmente la enseñanza de grado superior.

Por medio de su potencial educativo en la enseñanza, pretendía inculcar un espíritu de caridad hacia los mas desfavorecidos de la sociedad, a los cuales se consideraba dignos de ayuda, como ideal cristiano. Este ideal de caridad quedaría sembrado en alumnos de clase media-alta, ya que eran los únicos que podían acceder a una enseñanza superior sin tener que abandonar los estudios para ayudar a las faenas del campo, que es lo que ocurría en la mayoría de los casos de hijos de pequeños campesinos o jornaleros.

La cooperación entre clase alta e Iglesia, unidas en ayuda de las clases humildes, fructificaría luego, en las malas épocas, en las bolsas de caridad con que se intentaba paliar la situación de explotación, abandono y hambre, que periodicamente padecían los desposeidos de tierras en Andalucía.

La Iglesia como organismo estuvo siempre del lado del poder establecido, de la oligarquía, que era por lo demás la que estaba dispuesta a defender sus intereses frente a las nuevas ideas de reparto de los comunistas y anarquistas. No obstante hay que reconocer que, como siempre, tuvo en su seno individualidades comprometidas con las causas sociales justas, más acordes con los ideales cristianos; y que, por otra parte, la educación y mentalización de jóvenes en la enseñanza primaria y de bachillerato dió la semilla de un ideal sobre una sociedad mejor que, conectado con las influencias de las nuevas filosofías, darán lugar a posturas comprometidas con la causa social entre los intelectuales de la época que estudiamos.

Volviendo a los poderes fácticos más directos, podemos decir que oligarquía y caciquismo es una expresión que define lo que fué el bloque de poder de la época y la práctica política más común. Hay que reconocer que el caciquismo se ha llegado a considerar una seña de identidad de Andalucía en una época concreta y que incluso se ha originado en esta región, independientemente de su existencia coetánea en otras.

Entre las causas que se aceptan como determinantes del fenómeno caciquil andaluz estamos de acuerdo en destacar el analfabetismo, el control del mercado de trabajo por parte de los terratenientes derivado del sistema de propiedad de la tierra y la influencia de los principios anarquistas en el campesinado que no creía en la lucha política?.

El caciquismo fue un fenómeno sociopolítico que tuvo su tiempo histórico en la sociedad española del último cuarto del siglo XIX y el primero del XX. Revistió el aspecto de un ejercicio arbitrario del poder local, rectificando a su conveniencia la ley escrita. Corresponde sin duda a un país de estructura predominante-

7. BERNAL RODRIGUEZ, A.M. Andalucía caciquil y revolucionaria, en Historia de Andalucía, Ed. Cupsa-Planeta, 1981, pp. 20 y ss. 
mente rural. Este sistema servía perfectamente los intereses de una oligarquía para mantenerse en el poder, teniendo en cuenta que el sistema representativo concedía una proporción mucho mayor de representantes a los distritos rurales.

Hay un caciquismo persuasivo y un caciquismo coactivo. En Andalucía se dió más frecuentemente el segundo tipo. Puede decirse quizá que la población vivía una situación de debilidad política y consecuentemente estaba peor prepaprada para resistir.

\section{VIVENCIA DEL TERRITORIO Y PERCEPCIÓN DEL ESPACIO EN BASE AL STATUS SOCIO-ECONÓMICO}

Podemos decir que el mundo básico de la economía, lo que se conoce como infraestructura, junto a la percepción y vivencia del territorio, generan, (y son fruto a la vez de), un tipo de comportamientos y relaciones sociales específicas; y que, por otra parte, son portadores, asimismo, de una serie de rasgos culturales de orden material que denotan y refuerzan otros rasgos culturales de orden social y/ o simbólico.

Todos, siguiendo una gradación pero intimamente relacionados, conforman eI mundo de vivencias, relaciones, comportamientos, ideologías y sentimientos que caracterizan a un pueblo y lo identifican para sí mismo y ante los otros, sean estos otros, otro grupo, clase social, región o país.

En la Andalucía que estudiamos se daban unas vivencias de los aspectos materiales de la vida, según se formara parte de uno y otro grupo o clase social en que la propiedad de la tiera mantenía dividida a esta sociedad.

Según estos rasgos culturales, materiales o sociales, se identifican unos y otros, y se diferencian los poseedores de los desposeidos de tierra; y, sobre todo ello, se construye una determinada visión del mundo de una y otra clase, y del andaluz en general que vive en este medio ambiente y asimila esta cultura.

Un tema sobre el cual consideramos importante hacer algunas consideraciones en nuestra exposición es el de la territorialidad, debido fundamentalmente a que tiene por base el sistema de propiedad de la tierra en Andalucía y es obvio pensar que esto tiene que ver con el concepto y la percepción, así como con la vivencia, que de su territorio tiene el andaluz.

Creemos que el andaluz de la época que estudiamos tiene una relación muy especial con el espacio en que vive, una relación que le condiciona tanto vital como ideologicamente. Y es tan extrema y tan estrecha que le hace tomar posturas radicales en unos casos o conformismos fatalistas en otros. Esto referido a las clases "bajas", pues en lo concerniente a las altas, su dominio sobre el espacio, sobre el territorio andaluz, les confiere una prepotencia y un orgullo de clase muchas veces insoportable para los que lo sufren por un lado, y para los intelectuales críticos del momento por otro. 
La enculturación, la aproximación del niño a su sociedad a través de la educación primera que recibe en su familia, fundamentalmente de su madre, se constata totalmente distinta en los andaluces de una y otra clase. No hay que olvidar que la mayoría de los jornaleros y demás gente del pueblo son analfabetos, con una riqueza de vocabulario limitada y con una cosmovisión muy concreta que transmitir.

En relación a ésto, creemos que la vivencia del espacio por parte de los andaluces, de las dos clases que hemos considerado dicotómicas en todos los aspectos, es un tema a considerar en nuestro estudio, ya que el espacio está totalmente mediatizado por el sistema de propiedad de la tierra; y además estamos de acuerdo con Hall cuando afirma que todo, virtualmenter, lo que el hombre es y hace está relacionado estrechamente con la experiencia del espacio ${ }^{8}$.

En efecto, en la Andalucía que estudiamos y en relación al problema de la tieпra, la vivencia del espacio tiene un papel muy importante en el comportamiento y en la percepción de la realidad por parte de los individuos.

Desde la disposición y características de los núcleos de población de la Andalucía rural, donde se concentra la población trabajadora y desde donde se desplazan a grandes distancias para ir a faenar las tierras, probablemente de otros, hasta las estrecheces de las gañanías, donde tienen que pasar las campañas agrícolas los jornaleros por no poder salvar diariamente las distancias hasta sus casas; desde la concepción de los espacios públicos y privados a la inversa de como son en cualquier otro lugar, es decir, que los espacios públicos, como la plaza del pueblo, siempre suelen ser muy pequeños en relación a los privados (cualquier parcela de una propiedad del señorito), hasta la contradicción entre espacios sin cultivar, que invitan a pasear, incluso totalmente salvajes, que son a la vez espacios acotados, de propiedad privada, en los que se tiene prohibida la entrada, la vivencia del espacio condiciona la vida.

Se puede establecer otra relación entre la percepción del espacio y la situación de clase social del individuo, que a su vez refleja la condición de propietario o no de tierras, y su correlación con el uso del poder (del tipo que éste sea). Esta relación sería la de verticalidad, frente a la anterior, que se basaba más en la extensión y la posibilidad de dominio sobre el territorio. En efecto, dentro de los núcleos de población, se pueden reconocer diferencias de clase y poder entre las casas de los jornalero, de una sola planta, y las de los propietarios, de más de una planta y con importante balconada desde donde se "domina" toda una panorámica. El rico propietario en la Andalucía que estudiamos siempre mira desde arriba, ya sea en su casa, ya sea por los caminos (desde el caballo o el carruaje). Creemos que esto ayuda a fomentar el comportamiento de sumisión por parte de las clases "humildes", que están acostumbradas a quitarse el sombrero y bajar la cabeza cuando saludan al amo. 
La experiencia respecto al territorio y a la percepción del espacio interpersonal determina en cierta manera ciertos tipos de comportamiento que llegan a marcar diferencias entre un grupo y otro, o entre una clase social y otra. Estas diferencias de comportamiento hacen identificarse con un grupo y otro, de forma que llega a verse raro e incomprensible, que un individuo perteneciente a uno de esos grupos se comportara de igual forma que otra del grupo opuesto; por ejemplo en el caso del saludo, sería una altanería propia de bandolero por parte del humilde el hacerlo como el amo, y se consideraría un locura lo contrario.

El campesino andaluz, el desposeído de tierras sobre todo, tiene interiorizado el ideal de acumulación como garantía de estabilidad, prestigio y poder social, que le pueda permitir, alguna vez, un cambio en su estatus, al que aspira siempre, y que además se le presenta como claro ejemplo a seguir desde la clase dominante. El paisaje influye en el sistema perceptivo del hombre del campo en relación con su visión del mundo. Defendemos la idea de que una propiedad grande, inabarcable con la vista o de varias jornadas a pié, tiene que impresionar mucho al que no lo posee; y le da inseguridad, desarraigo. Por otra parte le confiere un poder al amo mayor quizás del que realmente detenta.

En efecto, en la Andalucía que estamos estudiando la mayoría del espacio pertenece a unos pocos, en todos los sentidos, es decir como espacio y como producción o base económica, casi la única de la región en ese tiempo, pero el resto de los andaluces, los que llamamos desposeidos" en este trabajo, perciben y sienten este espacio como su territorio, aunque no tengan dominio sobre él.

Lo que acabamos de comentar tiene alguna relación con las afimaciones siguientes de Jose Luis García acerca de la "exclusividad" como caracteríatica más sobresaliente de la territorialidad: hay una "exclusividad positiva y otra negativa. La primera de ellas indica el sentido de posesión o dominio (...). La exclusividad negariva hace referencia a aquellas situaciones territoriales de la que son sujetos los restantes grupos o entidades sociales. A una exclusividad positiva en relación con un grupo o subgrupo corresponde automaticamente una exclusividad negativa para el resto de los grupos o subgrupos, que es antiteticamente simétrica de la anterior"9.

En nuestro caso la exclusividad positiva estaría en manos de los poseedores de la tierra, los cuales tienen para sí el espacio material y los frutos del mismo, que son lo ùnico importante en una Andalucía sujeta a una economía de base agraria, lo cual a su vez los hace dominadores del territorio y detentadores del poder que ello conlleva. De sus dominios excluyen, (exclusividad negativa), en todos los sentidos, a la otra clase social, que sólo tiene acceso a ellos como mano de obra no siempre asalariada ${ }^{10}$.

9. GARCIA, J.L. Antropología del territorio, Taller Ediciones J.B., Madrid, 1976, pp. 29.

10. BELTRAN, E. Socialismo agrícola. Leyenda popular. Segunda parte de Manolín, Córdoba 1908. Ed. A. Calero, Madrid, 1979, pp. 93 y ss. 
Hemos podido apreciar que, junto a una aparente admiración o incluso sentimiento de envidia, la percepción y el padecimiento de esta exclusividad negativa es la raiz de todo el resentimiento del pueblo llano andaluz ante la prepotencia de los "pudientes".

Todo nuestro estudio está basado en la fuerza de una fuente de poder: la posesión de la tierra. Esta fuente de poder coincide con ser también la fuente de vida y de ingresos económicos de unos y otros andaluces, cada uno en el nivel de clase en que se encuentra. Es la infraestructura andaluza de la época, y quien la maneja es el amo del territorio, pues todo el territorio de la comunidad se ve orientado en su configuración por la infraestructura económica.

Aunque durante mucho tiempo ha sido así en Andalucía, dominadores y excluidos del territorio, o desposeidos, no tienen por qué ser los mismos siempre. Así pareció entenderse a principios del siglo XX, cuando los excluidos comienzan a percibir alguna posibilidad de cambio.

\section{DISTINTAS FORMAS DE VIDA: RASGOS CULTURALES E IDENTIDADES COLECTIVAS}

Todos los detalles de la vida cotidiana y los relativos a la satisfacción de las necesidades mínimas no hacen sino resaltar estas diferencias entre estos distintos andaluces. Resultan ser modos de vida que les hacen, logicamente, identificarse con uno y otro grupo, con unos y otros intereses de clase. Creemos que estas diferencias y esta situación de enfrentamiento han mantenido a Andalucía y a todos los andaluces anclados en el pasado y paralizados para una moderna evolución, sin duda portadora de mejoras para muchos y satisfacción y orgullo para todos. El egoísmo y la falta de visión de unos pocos, junto a la impotencia o incapacidad, por los motivos que fueran, de muchos, todo junto, logró que Andalucía no fuera ese paraiso de productividad que la hacía, de forma falsa, famosa en las mentes de los que no la habitaban.

Unos datos acerca de la vivienda, del vestido y del trabajo nos darán una idea más precisa de cómo todo ello puede moldear unas formas de comportamiento y una cosmovisión diferente en gentes que habitan una misma región, en andaluces que viven, aunque de forma diferente, de la misma tierra.

Las diferencias de formas de vida, sobre todo en sus aspectos materiales, entre individuos o grupos de diferente clase social es normalmente evidente para cualquier persona ya que se basan en un distinto poder adquísitivo, pero lo que queremos destacar aquí es que en la Andalucía de la época que estudiamos no se trata sólo de diferencias graduales entre los que tienen más y los que tienen menos, es que más que de diferencias se trata de contrastes, unos contrastes muy bruscos que se perciben y viven con violencia por causa, creemos, de dos factores muy impor- 
tantes a tener en cuenta para comprender formas de ser y de comportamiento. Estos dos factores serían la casi inexistencia de una clase media lo suficientemente numerosa como para que mitigara de alguna forma el contraste entre las otras clases antagónicas, por un lado: y por otro, el hecho de que dichas dos clases convivían estrechamente en una misma sociedad, de tipo rural y dependiendo del mismo medio de producción: la tierra.

Evidentemente al convivir los desposeídos de casa, comida y vestido literalmente junto a los opulentos y dependiendo de ellos sin apenas otra alternativa, al ver lo que comían y cómo vivían, se hace lógico pensar que las relaciones entre ambas clases fluctuaran desde una criticada sumisión sin dignidad a un rebelarse violento en cualquier ocasión aprovechable que conllevara una ilusión de cambiar un modo de vida por el otro, el deseado y el modelo a seguir. Y en el fondo de ello, como base de ese sistema y como llave de liberación del mismo, el ideal de todo andaluz: la propiedad de la tierra.

De la vivencia de los contrastes materiales nacen los sentimientos; de los comportamientos que ambos contrastes y sentimientos, generan surgiran las ideas e ilusiones de cambio.

Hemos de intentar conocer asimismo las vivencias de tipo social que, junto a aquellos factores materiales, conforman la vida de los individuos y clases sociales que estamos considerando. La interacción de ambos universos, el material y el social, dará lugar a determinadas visiones del mundo, (según la posición de clase social), y a determinadas identidades andaluzas.

Aspectos como la educación, el ejercicio del poder, el concepto del trabajo, la convivencia entre las clases en la comunidad, las relaciones y percepciones mutuas, entre otras cuestiones consideradas dentro de lo que se conoce como estructura social, pueden ayudarnos a comprender muchos estereotipos y muchas formas de pensar del andaluz de ayer y de hoy.

Lo que hace percibir con gran nitidez los contrastes entre las formas de vida para los andaluces de la época y para los estudiosos del tema de todos los tiempos es la estrechisima convivencia de los andaluces de ambas clases sociales en una situación que bien describe Blasco Ibáñez en las siguientes líneas:

"La campiña, dependiente de la ciudad, que abarcaba casi una provincia, era de 80 propietarios. En el resto de Andalucía ocurría lo mismo. Muchas familias de rancia nobleza habían guardado la propiedad feudal, las grandes extensiones adquiridas por sus ascendientes, con solo galopar, lanza en ristre, matando moros. Otras grandes propiedades hahían sido formadas por los compradores de bienes nacionales, o los agitadores políticos del campo, que se cobraban sus servicios en las elecciones, haciéndose regalar por el Estado los montes y los terrenos públicos sobre los cuales vivían pueblos enteros. En ciertos sitios de la sierra, encontrabanse poblaciones abandonadas, con las casas desplomándose, como si por ellas hubiera pasado una epidemia. El vecindario había huido lejos, en busca de la servidumbre 
del jornal, viendo convertirse en dehesa de un rico influyente los terrenos públicos que daban el pan a sus familias.

Y esta pesadumbre de la propiedad, desmesurada y bárbara, aún se hacía tolerable en ciertos lugares de Andalucía, por estar lejos los amos, por vivir en Madrid de las rentas que les enviaban aparceros y administradores, contentándose con el producto de unos bienes que no habían visto (...)

Pero en Jerez el rico estaba sobre el pobre a todas horas para hacerle sentir su influencia. Era un centauro rudo, orgulloso de su fuerza, que buscaba el combate, se embriagaba en él y gozaba desafiando la cólera del hambriento, para domeñarle como a los potros salvajes en el herradero"11.

Las relaciones de trabajo y de poder, firmemente apoyadas en una educación clasista, con una legitimación social y religiosa que impregna las mentes desde la infancia, junto a la estrechisima convivencia entre las clases sociales antagónicas, la cual genera una nítida vivencia de los contrastes en las formas de vida, explican en muchos casos características tales como la mentalidad clasista entre los andaluces en general, un cierto espíritu de servilismo entre los desposeídos junto a un afán por emular y conseguir las formas de vida de los señores, cierto caciquismo, el famoso fatalismo, y muchas de las explosiones violentas de la clase trabajadora contra lo establecido.

Sabemos que cada sociedad, con su cultura propia, contiene unas normas y valores, unas percepciones y unos conocimientos de las cosas que generan unos tipos de respuesta conductuales o de tipo afectivo, mucho de ello en relación a los estímulos interpersonales que se viven. La aceptación de dichas normas y valores, implica cierto grado de conformidad. Cuando la aceptación es obligada y no se posee la posibilidad de realización de cambios, o no se dispone, por los motivos que fueren, de inicitiva personal, podemos hablar de conformismo.

La clase jornalera andaluza ha sido criticada por conformista, por falta de iniciativa, pero no creemos que ello sea una característica étnica como han pretendido considerarla algunos, ni es fruto de la bonanza del clima, como afirman otros. La respuesta hay que buscarla en la imposibilidad material, por carencia de todo tipo de medios, y moral, por el atenazamiento de las mentes, que hacen que se esté esperando continuamente la aparición de la oportunidad.

Ello no quita que este sistema social también "se viva" como problema social y sea protestado, tácita o explicitamente, por la clase que lo sufre: los trabajadores del campo. Pero para ellos "el problema obrero estaba planteado en términos sencillísimos: ¡Pan y dinamita! Esto era lo único que necesitaban”12.

11. BLASCO IBAÑEZ, V. La bodega, Ed. Plaza y Janés, Barcelona, 1979, pp. 160.

12. DIAZ DEL MORAL, J. Historia de las agitaciones campesinas andaluzas, Ed. Alianza, Madrid, 1979, pp. 205. 
La citada característica de ingenuidad, junto a la falta de preparación en todos los sentidos quizá nos ayudaría a comprender el mesianismo, los movimientos y revueltas motivados por cosas concretas, independientemente de que sus necesidades fueran por ahí, y la dificultad para conectar con ideologías de miras más amplias, como la socialista, que dificilmente conseguían adeptos entre la clase jornalera andaluza.

Esto hemos de relacionarlo con el individualismo, otra de las características aplicadas al andaluz.

Una persona insegura, consciente de su "no saber", siempre tendrá miedo a ser engañado; tenderá a ser individualista y autosuficiente. Por otra parte, esta desconfianza y esta ignorancia pueden provocar un comportamiento tendente al inmovilismo y/o al extremismo. Es bien conocido entre las gentes del Sur la desconfianza hacia lo nuevo no solo a nivel ideológico, sino también tecnológico (por ej. recoger la naranja de forma más lenta y trabajosa, la forma tradicional frente a la moderna).

Como ya hemos apuntado en otra ocasión, no son sólo los intentos de cambio frustrados los que provocan esta forma de pensar; en realidad todo el proceso socializador, toda la educación que recibe el andaluz, lo lleva a pensar de ese modo. Veamos. El agente personal de la socialización más influyente es la madre. Imaginemos, en una Andalucía con escasa participación escolar, la enseñanza de cómo debe vivirse, en fin, el aprendizaje de normas y valores, en un gran cortijo donde una madre enseña a su hijo a ser caritativo con "sus" obreros, pero a no perder la autoridad ni el respeto; y en el otro extremo, en la gañanía, la madre enseña al hijo a levantarse en señal de respeto, pese al cansancio del duro trabajo, cuando aparezca el señor.

Además, cuando entre la clase trabajadora se aceptan las bases de lo establecido se habla de "individuos competentes", siendo la competencia la capacidad de adaptarse al entorno de una manera adecuada.

Cuando algunos individuos no se adaptan pueden unirse en "grupos informales", los cuales se organizan sobre la base de objetivos compartidos. Puede ser el caso de los líderes espontáneos de las revueltas campesinas, así como uno de los orígenes de bandas y bandoleros. El tirarse al monte era, muchas veces, la solución extrema de unos hombres que no encontraban lugar digno de ser vivido dentro de la sociedad que les tocó vivir. No creemos que todos los bandoleros o inadaptados que al parecer existían en la Andalucía de la época respondan a un mayor índice de criminalidad entre los andaluces, sino a unas necesidades básicas insatisfechas y a un determinado sentido de la libertad y del honor que no permite la humillación y la explotación a la que se ven sometidos la mayoría del resto de andaluces de clase trabajadora. Una prueba de ello es la admiración que despertaban estos hombres entre el pueblo llano (que en ningún lugar del mundo admira a criminales) como una especie de héroe épico. 
Unos de forma individual y otros, los líderes campesinos, intentando llevar tras de sí a toda la clase social oprimida, mediante huelgas y otras acciones, ambos ponían de manifiesto la existencia del problema social andaluz frente a un poder establecido reacio a aceptar cualquier cambio, al precio y con los medios que fueran necesarios.

Frente a estos "valientes", admirados por el pueblo llano, y locos y criminales desde la óptica de los poderosos, podemos apreciar el pesimismo y el desengaño que parecen inundar las almas del resto de los oprimidos y a muchos intelectuales ${ }^{13}$.

Por otra parte hay estudios que dejan constancia de que la experiencia de iniciativa-autonomía y la asunción de responsabilidades y decisiones en el trabajo tienen que ver con el desarrollo de la autoestima en la edad adulta ${ }^{14}$. Unas personas educadas para obedecer, a la fuerza tienen que perder iniciativa-autonomía. El jornalero no piensa, es decir, no debe pensar; trabaja con sus manos; no tiene por qué dar más. Es mejor mantenerlo en su universo limitado a cosas materiales e inmediatas y que no se malacostumbre. Esa es la filosofía del señor; y quizás venga aquí a colación un ejemplo del concepto de relaciones de clase que presenta el amo Dupont en la obra de Blasco Ibañez:

"Para Dupont el amo lo era por derecho divino, como los antiguos reyes. Dios quería que existieran pobres y ricos, y los de abajo debían obedecer a los de arriba, porque así lo ordenaba una jerarquía social de orden celeste. (...)

Yo no soy como esos otros amos que viviendo en perpetuo ahogo regatean el sudor al pobre. ¡Caridad, mucha caridad! Que se vea que el cristianismo sirve de arreglo para todo... Pero lo que me revuelve la sangre es que se pretenda que todos seamos iguales, como si no existieran jerarquias hasta en el cielo (...) Aún temblaba de cólera recordando cómo despidió a un tonelero, un mentecato adulterado por la lectura, al que había sorprendido haciendo alarde de incredulidad ante sus compañeros. (...) En Jerez nadie le ha dado trabajo por no molestarme, viendolo expulsado de mi casa, y ahora tal vez vaya por el mundo royendose los codos de hambre. Este acabará por echar bombas, que es el final de todos los que niegan a Dios. (...) Y ya sabemos lo que son los trabajadores: ¡Mala gente! Con ellos el pan en una mano y el garrote en la otra"15.

Esta filosofía aplicada a la vida real y a las relaciones de trabajo, de clase y sociales en general, puede darnos una idea de lo atenazadas que podían estar las posibilidades de cambio y de desarrollo para la mayoría del pueblo andaluz que padecía esta situación. Se estimulaba el miedo y la ignorancia entre la clase traba-

13. El final de la novela de Ruiz Maya: Los libertadores del campo, Imprenta de Juan Pueyo, Madrid, 1920, es un ejemplo de fatalismo pesimista en el intelectual.

14. MONTIMER, J. y LORENCE, J. "Ocupational experience in the self concept: A longitudinal Study" en Social Psycology Qyarterly, 42, 1979.

15. IBAÑEZ, B. o.c. pp. 25 y ss. 
jadora; así pues, no es de extrañar que uno de los objetivos más inmediatos que se propusieron los intelectuales "concienciados", (al igual que lo fué para los anarquistas), fuera la instrucción y el desarrollo del pensamiento en un afán por educar al verdadero protagonista de la vida andaluza: el pueblo llano.

Pensemos que Andalucía era una región eminentemente rural, con arraigados modos de vida campesinos, en la que muchas de las características aplicadas a las sociedades campesinas tienen cabida.

Como hemos ido viendo a lo largo de la exposicióu, los modos de vida materiales y la vida social, ambos teniendo por base unas relaciones de clase muy estrechas, todo ello queda constituído sobre la tierra andaluza, tierra en el sentido de fuente de vida, de territorio, de lugar de trabajo, etc.

Por tanto podemos decir que es, en definitiva, la relación con la tierra, en directo o a través de toda una serie de pasos intermedios (materiales o sociales), el origen de la cosmovisión del andaluz de una y otra clase. La visión que unos y otros tienen de su medio ambiente, físico y social, y de su medio de vida, es diferente según la posición social que ocupan, y según la calidad de propietario y desposeido.

Así pues, teniendo en cuenta todos estos elementos, podemos comprender que lo que para unos es placer, para muchos es dolor; que lo que para unos es un bien no apreciado (por su abundancia o la forma de lograrlo no se valora), para otros, la mayoría, es un bien limitadísimo, casi imposible de conseguir y sumamente ansiado: la propiedad de la tierra.

Hemos de decir también que todo ello se convierte en una relación pasional, en la que los sentimientos entran en escena continuamente.

\section{TIERRA Y PODER}

La posibilidad de cambio social que tenían en sus mentes muchos andaluces de principios de siglo debía tener como primer paso el hacerse con el poder y sobre todo, con la propiedad de la tierra.

En efecto el tema de la tierra era la base del poder social en Andalucía.

La posesión de la tierra ha conferido en Andalucía un poder importante, vital para la clase dominante, que se ha manifestado en la práctica de diferentes formas: el poder de recompensa (supone una cierta habilidad del dominante; es el empleado por el "amo bueno"); el poder coercitivo (implica el empleo del castigo como escarmiento. Suele ser fruto del miedo de los poseedores); el poder legítimo (como un derecho de la clase "pudiente" y conlleva la aceptación de la estructura social que implica una jerarquía de autoridad son bases del poder legítimo).

En el ethos andaluz, la inteligencia y la casta han sido factores destacados en relación al poder; pero hay que matizar. 
En un pueblo tradicional y mayoritariamente analfabeto, donde sólo los "pudientes" tienen acceso a una educación letrada, es frecuente confundir la inteligencia con esta educación y quedarse impresionado y sometido ante una buena forma de hablar y expresarse. Esto es válido aplicado a los propietarios y a los líderes políticos, sean de la clase que sean. El ser instruido ha ejercido una gran fascinación en el andaluz analfabeto.

En cuanto a la casta también ha sido siempre un valor cultural importante en Andalucía. Es una palabra muy usada e impresa en el subconsciente colectivo, aún hoy: "de casta de señoritos", o "de buena casta". Este último empleado más frecuentemente entre los "humildes" con un significado más que de posición social, de posesión de honor, opuesto al anterior, que tiene más bien un matiz despectivo. Es curioso destacar que los pudientes emplean menos este vocablo y cuando lo hacen es para referirse a animales (toros, caballos o perros de caza).

$Y$ en cuanto a las características físicas conviene destacar en un pueblo con un gran sentido de la estética, la importancia y la fascinación de un buen porte, una buena figura, una gracia. Esto es más fácil tenerlo o acercarse a ello si se tiene dinero.

Por último comentamos otros dos tipos de poder, muchas veces coexistentes, y que aparecen frecuentemente en las relaciones de clase y laborales entre los andaluces: el poder referente y el poder de experto. El primero se basa en la identificación con el detentador de poder; (si P (=propietario) es un grupo atrayente y D (=desposeido) tiene un sentimiento de dependencia e inferioridad puede darse este caso: "quiero ser como P y lo conseguiré mejor si me conduzco como él y creo en lo que él cree"). Hemos podido detectar esto entre algunos tipos de capataces, manijeros y administradores de cortijos, aunque hay que añadir que la aspiración a ser como el amo está en todo el individuo que no lo es. (Aquí el sentido de ser como el amo es el de "tener" como el amo). En este caso no existe ni castigo ni recompensa.

Por su parte el poder de experto en el caso que nos ocupa está relacionado con el analfabetismo y la admiración por la capacidad de ser alguien en la vida.

A través de determinados valores culturales, ideológicos y religiosos se ha estimulado la conformidad y se ha legitimado la coerción haciendola aparecer como el estado social natural, de forma que se hace creer que siempre ha sido y será que mandan los que tienen y obedecen los que no tienen.

Una de las características sobresalientes del pueblo andaluz, y que llama mucho la atención fuera de las fronteras regionales es la tolerancia, casi la sumisión y capacidad de aguante de muchas situaciones adversas límite. Creemos que esto tiene relación directa con el desigual reparto de poder, reflejo de la desigual propiedad de la tierra. Ello conlleva comportamientos específicos y percepciones concretas de la realidad, que muchas veces no se entienden si no se tienen en cuenta estos datos referentes a la infraestructura de esta compleja sociedad. 
Estas diferencias en el ejercicio del poder y la influencia sociales producen distintos efectos en cada uno de los dos grupos que tratamos: en el agente dominante implica privilegios, da seguridad; en el sujeto dominado produce una marca de inferioridad. Al recibir poder de recompensa se produce una tendencia a aceptar los standars del agente de poder (identificación); con castigo aumenta la inseguridad personal e interfiere el aprendizaje de criterio propio; se dan conductas de congraciamiento. Cuando el bienestar depende de P, éste puede o no obstaculizar su consecución lo que conlleva frustración y falta de libertad.

Los miembros individuales del grupo con posiciones de bajo estatus tienden a comunicarse hacia arriba siguiendo conductas que podríamos llamar de apaciguamiento. A largo plazo, cuando el poder es vivido como anulador genera sentimientos de incapacidad, debilidad y escepticismo y apatía, o, por el contrario, puede crear en el individuo sujeto a ese poder fuertes sentimientos de agresividad.

La respuesta de debilidad y apatía, que es la que está mayor tiempo establecida, está relacionada con la debilidad de poder político y con una situación familiar de subsistencia, en la que no es posible arriesgar incluso la vida de la mujer y los hijos para luchar por esta cambio de situación.

Así pues muchas veces se acaba aplicando el refrán de "Mas vale pájaro en mano que ciento volando", aunque esto suponga merma en la dignidad humana y aparente aceptación de una realidad que se vive cotidianamente como injusta.

Solo cuando las condiciones de opresión y mala vida llegan al extremo y atacan el estado de subsistencia en que viven las familias de jornaleros de primeros de siglo, es cuando salta la respuesta agresiva, que siempre es fruto de un estado de frustración, el no poder más porque ya no se tiene nada que perder, porque la única posesión, la familia, está en peligro. Es entonces cuando se dan los estallidos violentos en el campo, aprovechando una coyuntura favorable de debilidad del fuerte, (época de cosecha) o de fuerza del débil, (arcas llenas en las organizaciones obreras).

La respuesta no es siempre agresiva porque "mientra er cuerpo aguante" se mantiene la situación.

Existe un sentimiento fatalista que es a la vez causa y efecto de esta pasividad e inmovilismo. La única salida que ve el campesino-jornalero de la época es la inversión del orden social, pero las veces que lo intenta fracasa. Son estallidos más o menos organizados, alentados por líderes de izquierda, y en esta época, (después de 1917), estimulados por el éxito de la Revolución Rusa, pero que acaban siempre con la aplastante fuerza del poder político-policial del fuerte y con la compra por el poder y corrupción de algunos líderes, los cuales en muchas ocasiones defendieron más los intereses de partido que los de la gente del campo.

$Y$ vuelta a seguir con la vida de siempre tras un nuevo fracaso.

En otro orden de cosas, creemos que es de interés destacar la importancia de la vivencia cultural y la convivencia en los distintos modos de vida que hacen que "desde una perspectiva sociocultural, los sectores campesinos integrados por pe- 
queños propietarios, arrendatarios y aparceros son asimilables al proletariado rural. Todos ellos, al margen de sus diferencias de intereses, consecuencia de sus distintas posiciones en las relaciones de producción, sienten, perciben y entienden la explotación desde una misma postura vital: aquella creada por sus formas y modos de relación social, producto de su común cultura campesina"16. Es decir, que una misma forma de ver la vida puede ser importante a la hora de concebir un cambio social, aunque esto no funcione en todas las ocasiones cuando el cambio se presenta muy conflictivo y puedan peligrar los bienes personales.

De cualquier forma pensamos que en Andalucía el pequeño propietario de tierra se solidariza con el jornalero no sólo en razón de la común vivencia cultural, sino también, y quizá como primer motivo, para sumarse a la oposición ante el omnipotente poder del amo, al que, de forma indirecta, están igualmente sometidos. Podríamos decir que es el mismo caso de los intelectuales, los cuales no pertenecen a la cultura campesina, pero en muchas de sus actividades se encuentran sometidos a los intereses de la oligarquía andaluza. No son sólo relaciones de producción o laborales, son relaciones en las que el poder económico, político, social, e incluso ideológico, está todo de una parte, en manos de una clase, los poseedores de la tierra, que hacen además, en este tiempo, un uso indebido y abusivo de todos estos poderes.

En este estado de cosas podemos afirmar que detrás de todas estas relaciones de estratos o clases sociales existe un estado latente de conflictividad que entre explosión y explosión, en los periodos de calma impuesta, se manifiesta y percibe en ambas clases en actitudes y sentimientos de sumisión y prepotencia; envidia y compasión y toda una serie de valores y pasiones contrapuestos, contrastados y fuertes, que configuran un modo de ser y de actuar en el andaluz de una y otra clase social.

Una clase y otra se tratan estrechamente y reaccionan estimulados por las acciones mutuas. A principios de siglo, con las nuevas ideas sociales, los intereses de clase se van definiendo a golpe de acciones aisladas, lo cual les hace unirse entre ellos, los individuos, para defender dichos intereses, lo cual, a su vez, hace que la conciencia de clase se vaya gestando y afianzando.

\section{ACTITUDES RESPECTO AL PROBLEMA DE LA TIERRA: CONFLICTIVIDAD}

Todas las descripciones de la sociedad andaluza de la época nos hablarán de lo mismo: el despotismo y el aguante, los abusos y el odio soterrado; la molicie y la

16. SEVILLA GUZMAN, E. y PEREZ YRUELA, M. "Para una definición sociológica del campesinado", en Agricultura y Sociedad, 1, Octubre-Diciembre, 1976, pp. 220. 
falta de interés por la región y por los demás entre los poderosos frente al desánimo de los que nada pueden.

Todo ello en ese ambiente de sumisión, ignorancia, paternalismo e impotencia individualista. Es un mundo en el que parecen atisbarse aires nuevos en la ilusión y la posibilidad de cambio predicadas por unas nuevas ideas y avidamente aceptadas por los oprimidos necesitados de algún cambio.

Existe cierta admiración hacia el pudiente, al que se envidia de forma imprecisa y al qne se quisieran asemejar los menos favorecidos. En Andalucía este afán por ser o parecer igual que el señorito se puede apreciar incluso hoy día, apareciendo de forma muy evidente en las fiestas y romerías como por ejemplo el Rocio, donde se dan muchos casos de imitación de los elementos relevantes por su condición social por parte de gentes de escalafón inferior, ya sea en el vestir, como en la forma de comportarse, etc. Pero esto sería tema de otro lugar. Baste aquí reseñar que junto al odio soterrado dentro de los más oprimidos, encontramos indicios de una cierta admiración, no por las personas sino por los modos de vida que se desearían llevar. Esta admiración y afán de emulación se da más claramente entre los que hemos llamado desclasados (capataces, aperadores, manijeros, etc.), que ven quizá más factible la posibilidad de alcanzar algunos signos de señoritismo, aunque sean sucedáneos y exteriores.

Es un círculo vicioso en el que la propiedad de la tierra es el centro. Alrededor del sistema de propiedad giran la molicie del gran terrateniente que no cultiva sus terrenos dedicados a ocio, y la desgana del obrero, que no participando en las ganancias de lo que cultiva de una forma proporcionada a su esfuerzo, ve en la tierra el origen de todos sus males. Indudablemente Andalucía, su riqueza, su autoestima y su consideración en el exterior se resentiría de todo esto.

No pretendemos aquí hacer un análisis de lo que fueron los conflictos campesinos andaluces de principios de siglo; hay ya muchos y buenos estudios sobre ello. Lo que nosostros queremos precisar es la relación que tienen entre sí y con dichos conflictos, los diversos elementos que, hemos considerado básicos para comprender la idiosincracia, la cultura y el comportamiento de un pueblo, a saber, el problema de la tierra, la estructura social en dos clases dicotómicas, y la vivencia y expresión cultural de ambos.

Por tanto, la referencia que hacemos aquí de los conflictos está en relación al problema de subsistencias que genera el problema de la tierra y en relación a la lucha por el poder, asimismo basado en el problema de la tierra. Todo ello, siempre, según la percepción que tuvieron los contemporáneos de los hechos, los andaluces del primer tercio del siglo XX.

Entendemos los conflictos como una vivencia y manifestación de todas las tensiones generadas en la Andalucía de la época entre los elementos antes citados.

Nosotros pretendemos relacionar estructura socioeconómica y problema social, considerando el movimiento obrero, es decir, los conflictos, como una manifesta- 
ción del precario equilibrio en que se mantienen los anteriores niveles, los antedichos económico y social.

El cada vez mayor desnivel entre población total y agraria en aumento y recursos agrarios estancados, en declive o insuficientemente desarrollados, produce las consiguientes tensiones, que en épocas de extrema gravedad se convierten en verdaderos conflictos "cuasi-revolucionarios ${ }^{17 "}$ ".

La conflictividad campesina andaluza es difícil de analizar. Diferentes autores no se ponen de acuerdo y achacan a distintas causas los levantamientos que se dieron en el agro andaluz. Mientras unos defienden el hambre como causa principal, otros rechazando este punto de vista, prefieren dar el protagonismo a los aspectos ideológicos y la conciencia de clase. Nosotros pensamos que no se descartan mutuamente, y que se dan unos y otros dependiendo de unas circunstancias y unos tiempos. Por ejemplo, a principios de siglo, en 1905, la importancia del medio físico, con la fuerte sequía, y la consiguiente crisis de trabajo y subsistencias, tuvieron el principal protagonismo; mientras que en 1918, junto a problemas laborales y económicos, los aspectos ideológicos tuvieron una importancia vital en las revueltas.

Aunque el "sueño del reparto" dominase muchas mentes entre los campesinosjornaleros, las reinvindicaciones eran muy precisas y no siempre portadoras de la idea de subversión total ni del cambio de relaciones de producción. Se da, en cambio, una progresiva adquisición de una conciencia de clase, aunque solo fuera en un grupo de vanguardia. La clase trabajadora se mantiene aislada como tal, con escasa relación con las clases medias y sólo una cierta aproximación con los intelectuales, siendo éstos los más interesados en contactar.

La mayoría de los aspectos de la vida campesina que los intelectuales parecen percibir más nitidamente, o al menos parecen impresionarles más, son los relativos a las formas de vida material de los jornaleros y a las relaciones de podersumisión a que están sometidos. Ello se pone de manifiesto en todos los textos analizados, casi todos portadores de un inconformismo apasionado ante la visión de tanta injusticia, al tiempo que toman claramente partido por la clase oprimida. Para ellos, todo esto explica los conflictos y la actitud campesina ante la vida; y todo ello tiene asimismo como explicación y causa el problema de la tierra.

Tradicionalmente se ha achacado a la existencia del latifundio, la causa de los conflictos. No es este en realidad, sino la latente competitividad por el luso de las tierras y el eterno deseo de poseerlas. Cuando algún andaluz se ve en sus manos con el uso y disfrute del producto de unas tierras, es decir, se convierte en pequeño propietario, es curiosa su actitud respecto a la clase dominante y respecto a los jornaleros y sus conflictos. Tal actitud se podría resumir en un aferrarse a la tierra con todas sus fuerzas, de forma que luchará contra el amo y el latifundista, junto

17. MARTINEZ CUADRADO, M, o.c. pp. 131-132. 
a los jornaleros, cuando las peticiones de éstos les favorezcan o no les perturben su estatus, sobre todo en cuestiones relacionadas con el reparto de poder y demás temas relacionados con la justicia.

Por contra, estos mismos labradores "de clase media" serán los más acérrimos defensores del orden establecido, cuando se toque el tema del reparto de tierras o la colectivización.

Por otra parte podemos decir que la represión violenta de los conflictos, sobre todo de las manifestaciones pacíficas, era a la vez consecuencia y causa de aquellos, puesto que acentuaba el sentimiento de odio y hacia más evidente la situación de dominación e injusticia padecida por los de abajo con el abuso de los de arriba. Así pues, las represiones servían para aniquilar el movimiento momentaneamente, pero tenían un proceso de retroalimentación que guardaba resentimientos para la próxima oportunidad de expresarlos, y además estimulaba el sentimiento de unión entre la clase trabajadora que sufría la represión en masa (es distinto el efecto de la represión sobre los individuos).

No se consideraban tan peligrosas las reivindicaciones políticas, porque contra ellas los grandes andaluces tenían sus escudos en el poder central del Gobierno y manejaban las leyes. En cambio, las de orden social eran portadoras de todas las ideas y sentimientos posibles que la experiencia del pueblo andaluz había desarrollado en su conciencia histórica. Toda la cosmovisión, el Ethos y las vivencias reales, junto a las expresiones de todo esto, directa o simbólicamente, de forma consciente o inconsciente, se hallaban presentes en los conflictos de tipo social, los cnales, además, tenían la facultad de sensibilizar al resto de la sociedad.

Respecto a los detentadores del poder se tienen dos tipos de percepciones fundamentalmente: mientras el odio al señorito es porque este representa todas las frustraciones relacionadas con el problema social, y es, además el propietario y dilapidador del bien ansiado: la tierra; en el cacique se personifica el abuso de poder y todas las cuestiones relacionadas con la vivencia de la injusticia.

En definitiva el andaluz medio, del pueblo llano, ha tenido una relación especial con su territorio, sobre el cual vivía pero sobre le que tenía apenas algún o ningún poder desisorio; o estaba invadido, o estaba colonizado o estaba mal aprovechado en manos de unos andaluces de nombre pero más identificados con la vida de la villa y corte de Madrid. Esta relación con su territorio, con sus tierras, que no son suyas, marcan de una manera singular la forma de ser y actuar del andaluz ante cuestiones de toda índole: conducta social, compromisos políticos, relaciones de clase, etc.

Y marca muy profundamente porque no es una relación superficial, sino vital, en el más literal sentido de la palabra, para la gran mayoría de los andaluces, qne son los desposeidos; y también vital, en el sentido más amplio de una determinada forma o nivel de vida, para los poseedores; una forma de vida que no pueden dejarse arrebatar, entre otras muchas razones porque la alternativa que les presentan no es muy "apetecible". 
Muchos andaluces y no andaluces de la época, tuvieron conocimiento del problema de la tierra en Andalucía. La región tuvo un destacado protagonismo en la historia de España del primer tercio del siglo XX por causa fundamentalmente del problema de la tierra. Este problema estructural, en unión a nuevas ideas sociales asimiladas por la clase trabajadora y a posicionamientos de tipo nacionalista entre algunos elementos destacados de las clases medias urbanas, todo ello en relación con los conflictos derivados de la situación socioeconómica de la región, llegó a convertirse en un importante catalizador de la conciencia de identidad andaluza.

\section{RESUMEN}

En relación con la visión del mundo y el Ethos del pueblo andaluz se encuentra el tema de la tierra.

Andalucía, a principios de siglo, es una región eminentemente rural, con arraigados modos de vida campesinos, en la que muchas de las características aplicadas a las sociedades campesinas tienen cabida.

Las bases materiales de la existencia y la vida social, ambos teniendo por base unas relaciones de clase muy estrechas, todo ello queda constituído sobre la tierra andaluza, tierra en el sentido de fuente de vida, de territorio, de lugar de trabajo, etc.

Por tanto podemos decir que es, en definitiva, la relación con la tierra, en directo o a través de toda una serie de pasos intermedios (materiales o sociales), el origen de la cosmovisión del andaluz de una y otra clase social: propietarios o jornaleros. La visión que unos y otros tienen de su medio ambiente, físico y social, y de su medio de vida, es diferente según la posición social que ocupan, y según el estatus de propietario en el campo o el de desposeido de tierras.

Todo ello se convierte, en la época que tratamos, en una relación pasional, en la que los sentimientos entran en escena continuamente: desde la recogida de la cosecha con desgana, hasta el trato despótico del amo o del capataz. Todo, como decía un jornalero, se hace un nudo en el estómago cuando se está trabajando, o cuando se regresa a casa sin jornal por estar en paro.

Los que más sienten el peso de la tierra son los que más la anhelan, pero quizá no tanto como medio de producción, en sentido económico, sino como poder y modo de ascensión social. Tener tierra es ser alguien en Andalucía. 